T. Jarimo and H. I. Kulmala. 2008. Incentive profit-sharing rules joined with open-book accounting in SME networks. Production Planning \& Control, volume 19, number 5, pages 508-517.

(C) 2008 by authors and (C) 2008 Taylor \& Francis

Preprinted with permission.

This is an electronic version of an article published in Production Planning \& Control, volume 19, number 5, pages 508-517. Production Planning \& Control is available online at:

http://www.informaworld.com/smpp/

http://www.informaworld.com/openurl?genre=article\&issn=0953-

$7287 \&$ volume $=19 \&$ issue $=5 \&$ spage $=508$ 


\title{
Incentive profit-sharing rules joined with open-book accounting in SME networks
}

\author{
T. JARIMO* and H. I. KULMALA \\ Nokia Corporation, P.O. Box 226, FI-00045 Nokia Group, Finland \\ VTT Technical Research Centre of Finland, P.O. Box 1000, FI-02044 VTT, Finland
}

(Received 00 Month 200x; In final form 00 Month 200x)

\begin{abstract}
Profit-sharing rules applied together with open-book accounting are a synergetic combination that encourages SME networks to continuous innovation. This paper studies profit-sharing rules that work as incentives for cost reduction in networks. We describe a case study of a steel-roof manufacturing and assembly network, where profit sharing became relevant shortly after open-book accounting was successfully implemented. Moreover, we present a dynamic game theoretic model for the study of the desired characteristics of profitsharing rules in such networks. We find that, under quite general assumptions, profit-sharing rules need to satisfy certain conditions in order to encourage the network partners to announce their cost-reducing ideas immediately. A suitable and simple profit-sharing rule is the combination rule which rewards the innovator and the target of cost reduction.
\end{abstract}

Key words: Subcontractor network; Incentives; Profit sharing; Game theory; Continuous innovation; Open-book accounting

\section{Introduction}

Business is moving from the competition of individual firms towards that of company networks (Gulati et al. 2000). Nevertheless, means to support continuous improvement and innovation in inter-organisational relations are scarce (Boer et al. 2005, Cagliano et al. 2005). A form of network benefit is overall cost savings, which can be used to increase the profitability of the network partners or to improve the network's competitive position by reducing end-product price (Mouritsen et al. 2001, Kajüter and Kulmala 2005). However, cost savings are not created automatically. Instead, there may be the need for explicit incentives

*Corresponding author. Email: toni.jarimo@nokia.com

$$
\begin{gathered}
\text { Production Planning and Control } \\
\text { ISSN 0953-7287 print/ ISSN 1366-5871 online (C)2007 Taylor \& Francis Ltd } \\
\text { http://www.tandf.co.uk/journals } \\
\text { DOI: } 10.1080 / 09537280 x x x x x x x x x x x
\end{gathered}
$$


for innovation (Gertsen 2003, Rese 2005).

Specifically, Rese (2005) states that there is an active need for explicit profit-sharing rules, because overall cost reduction and efficient cost management as such are not enough to motivate network partners into sustainable arrangements, such as open-book accounting, which support continuous innovation. Our case example described in this paper also supports this view. The case network consists of a principal who manufactures and sells steel roofs, which the subcontractors install at construction sites. Here, the successful implementation of open-book accounting raised the need for explicit profit-sharing rules.

In this paper, our objective is to find profit-sharing rules that work as incentives for network partners to reduce their costs immediately when opportunities for cost reduction are identified. In general, profit sharing and incentive contracts have been studied extensively in the field of game theory. For instance, Corbett and DeCroix (2001) study the interesting case where the principal wants to save through decreasing the amount of materials purchased from suppliers. They show that incentive contracts can increase the profit of the supply chain, but do not necessarily result in reduced consumption. Cachon and Lariviere (2005), in turn, focus on benefit sharing with retailers. In particular, they compare revenue sharing to other supply-chain contracts, concluding that in some cases revenue sharing may be administratively too expensive. Jarimo et al. (2005) have studied profit sharing in the context of network cost-reduction. Their approach measures the size of the cost reduction and rewards the network partners accordingly.

Another context where incentive contracts have been studied is one-of-a-kind project procurement (e.g. Scherer 1964, Bajari and Tadelis 2001), but these studies are not completely eligible for partnership networks, which should be seen as processes rather than entities (Cousins 2002). Bakos and Brynjolfsson (1993), in turn, study supplier investment-incentives in a setting where the principal controls the number of suppliers. In an open-book network it is, however, infeasible to continuously make the suppliers compete against each other.

The remainder of this paper is structured as follows. Section 2 describes a case network where openbook accounting was successfully implemented and the need for profit-sharing rules emerged. Section 3 constructs a dynamic game-theory model for cost reduction and studies suitable profit-sharing rules. Sec- 
tion 4 discusses the managerial implications of our theoretical results and Section 5 concludes.

\section{Empirical description on the incentive problems}

\section{$2.1 \quad$ Case background}

The case network, here Roof \& Steel, consists of the principal (Roof \& Steel Ltd) and seven of its primary subcontractors (referred to as roof assemblers). The network had been created in the mid-1990s. In 2004, however, Roof \& Steel decided to reorganise the network so that the roof assemblers would become more aware of their role in the business.

The structure of the network is such that Roof \& Steel pays the roof assemblers for their assembly work, and the house builders or renovators pay Roof \& Steel for all the work and the material. The roof assembly firms do not own the roof materials in any phase. Roof \& Steel delivers the material to the construction site where the roof assemblers then perform the assembly work.

In 2004, the annual sales of Roof \& Steel was about 420M€ and it employed ca. 900 people (the proportion of sales in the roof business was ca. $2 \%$ ), while the average annual sales for roof assemblers was about $0.3 \mathrm{M} €$ and the average number of employees was four. Thus, the network is a regional, operative SME network with hierarchical structure (Pfohl and Buse 2000). In the roof business, Roof \& Steel delivers customer service, design, production, logistics, and everything else but the roof assembly and sales.

\subsection{Generic cost model and process development simulation}

The interests of Roof \& Steel and the individual roof assembly firms met as regards costs and quality of the assembly service. Firstly, Roof \& Steel wanted to make the assemblers more aware of the cost structure of the assembly work and, as a result, to make them more active in controlling the costs of the overall operations. Most of the roof assemblers worked exclusively or primarily for Roof \& Steel. The direct cost was controlled by Roof \& Steel who owned all roof material. The assemblers were responsible for all wasted material and the assemblers paid their employees only for performed working hours. Hence, direct costs were known quite well in each assembly order. 
Because the pricing between the assembly firms and Roof \& Steel was based on an agreed lump sum per assembled roof, the roof assemblers calculated all their indirect costs and split the annual sum equally between the different assemblies. The lump sum was negotiated with Roof \& Steel based on two parameters: The size (square meters) and the complexity (number of corners and skylight windows) of assembled roof. Roof \& Steel paid these lump sums according to same principles to all assemblers because they expected competition between assemblers to keep costs down. This procedure caused an increase in assembly costs, because the assembly firms did not actually control their indirect costs, which represented a high percentage of total costs. Instead, they only calculated them afterwards and tried to add them to the next year's margin in negotiations. At the same time, the assembly firms were concerned about their competitiveness because Roof \& Steel expected a decreasing price trend while the assemblers' group-level costs seemed to be increasing. In this situation, most of the assembly firms felt helpless because they did not find a solution for reducing the costs of direct work. Therefore, in order to deepen the understanding of end customers' profitability, the cost structures of roof assembly work and roof assembly firms were modelled.

Secondly, a new cost model for the total costs of an assembly firm was developed so that all their cost elements were expressed as parameters that could have different values. This kind of simulation means, for example, that by inserting a new purchase price and new usage (driving kilometres) for the assembly groups' lorries, the new total annual costs of assembly firms were simulated. These total costs were further assigned to individual assembly sites. Similarly, the total network could easily simulate the cost-saving potential by changing the parameters of any of the simulated issues. For example, moving from a too big office to a smaller one (half of the size) could result in annual savings of $4200 €$ for a roof assembler because the lower rent per month is assigned to assembled roofs instead of the higher rent.

The novelty in the simulation was the exact figures for each decision and the easiness to make this kind of simulation. Now, the roof assemblers could easily compare whether e.g. moving to a smaller office would bring more or less savings than reducing reclamations. At the network level, Roof \& Steel could focus on recommending practises that would lead to the highest cost-saving potential.

Thirdly, the annual sales to Roof \& Steel were added to the model in order to control and simulate profit 
as well. By adding the sales, the assembly firms were able to simulate also the work load for assembly groups and individual employees, and to calculate how many new roof assemblies (sales) are needed in order to launch a new assembly group profitably.

\subsection{Who gets the benefit?}

After the new cost model and the simulation tool had been developed, an active discussion and analysis began regarding the impact of alternative decisions on the companies' total profitability. An assembler captured the point: 'I did not know that the customer complaints have so much influence on the poor profitability'. In general, the cost awareness increased by the simulation. Even though the overall cost structure of the assembly firms was not very well-known before the development process, the most important benefit for them in the future is expected to result from the simulation, because in all decisions regarding the simulated parameters, the assembly firm can now foresee the economic effect on the annual result before making the decision.

After training, all assemblers decided to adopt the new cost model and the simulation. Since the assemblers were shown that they can improve their profitability through changes in the process or in the firms' infrastructure, they may also now have more incentives than before to reduce costs and to execute the commonly agreed actions. The awareness regarding cost reductions has primarily relied on removing the profitability advantage from the assemblers to Roof \& Steel by reducing assembly prices. With the cost structure simulation, assemblers could see that reducing prices does not have to mean reducing profitability. In contrast, a win-win situation of reducing prices with half of the cost reductions was simulated.

After the process, the most significant problems from Roof \& Steel point of view were: (i) they had invested alone in the network development, (ii) all roof assemblers did not immediately take advantage on the evident cost-reduction opportunities, and (iii) some roof assemblers did not commit to the decreasing prices. There were no formal agreements or rules between Roof \& Steel and the assemblers on how to proceed with the results of new cost simulations. This led the assemblers to unnecessarily postpone their cost-reduction efforts and to hold the old pricing agreements. 
Hence, there seems to be an actual need to formalise such profit-sharing rules that provide incentives for all network members to immediately bring all their process development ideas into the joint discussion. Otherwise the open-book accounting case may lead to exploitation of a partner or misuse of confidential information in other business relationships.

\section{Game theoretic model of cost-reduction options}

\subsection{Sharing profits from cost-reduction options}

As described in the above case, open-book accounting increases the chances of identifying actions that reduce costs in the operations of one or more partners. We call the possibility to reduce costs a costreduction option. For instance, a cost-reduction option would be the opportunity to terminate the lease of a storage space if no inventory is needed. We say that the cost-reduction option is exercised if the necessary actions are taken so that costs are actually reduced. In the lease example, the termination of the contract exercises the option. Moreover, the owner of an option is the one who has the potential to exercise it.

Naturally, it would be optimal for the network if all cost-reduction options were exercised immediately when identified. However, the network partners may be unsure about the effect of cost-reduction on their profits, which may cause the postponing of exercise or even abandoning the options. In the following, we extend the model of Jarimo et al. (2005) and study the desired characteristics of profit-sharing rules when successive cost-reduction options may emerge. Specifically, we consider a setting where all network partners identify cost-reduction options according to some stochastic process and the sizes of the corresponding costsavings are random too. Thus, if all options are exercised as soon as they emerge, the total costs follow a decreasing cumulative stochastic process. For instance, figure 1 depicts a realisation of such process.

The exercise of a cost-reduction option triggers the need to share the cost saving among different objects. In practise, the possibilities are, first, to increase the margin of the subcontractor; second, to increase the margin of the principal by reducing the price paid to the subcontractor; third, to decrease the price of the end product. In the latter case, the subcontractor's and the principal's margins stay unchanged, but the competitiveness of the network increases due to the reduction of the end-product price. 


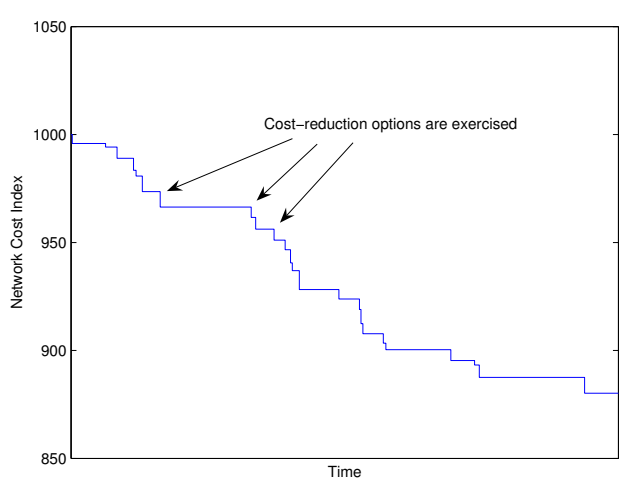

Figure 1. The network's cost-reduction process

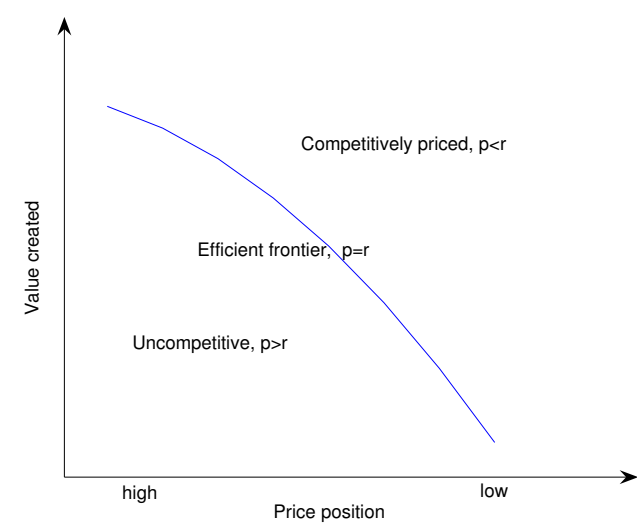

Figure 2. The market's efficient frontier (Porter 1996)

In competitive markets, the end-product price needs to be in relation to the value delivered to the customer (e.g. Porter 1996, figure 2). Moreover, there is no reason to reduce the end-product price more than what it requires to outperform rivals. Thus, it makes sense to set an aspiration level for the endproduct price, and when this level is reached, the surplus from cost reductions can be used to increase the profits of the network partners. Naturally, this requires continuous monitoring of the market positions in order to be aware of one's own position relative to competitors.

\subsection{Mathematical formulation of profit sharing}

Formally, let us denote the network's principal by $M$ and the set of its subcontractors by $N=\{1, \ldots, n\}$. Let $s$ denote a total saving due to the exercise of a cost-reduction option. Moreover, let $x_{i}$ denote the share of $s$ allocated to increase the margin of subcontractor $i$, let $x_{M}$ denote the principal's share, and $x_{p}$ the share allocated to end-product price-reduction. Hence, $\sum_{i} x_{i}+x_{M}+x_{p}=s$. The problem is, therefore, to determine the allocation $\mathbf{x}=\left(x_{1}, \ldots, x_{n}, x_{M}, x_{p}\right)$, where $x_{i}$ is the profit to company $i$ from the exercise of cost-reduction option $s$.

Let $r(t)$ denote the desired end-product price level, or reference price at time $t$ (figure 2). Moreover, let $p(t)$ denote the network's end-product price at time $t$, commensurable to $r(t)$. The reference price is the lowest market price of a competing product with an equal customer-perceived value as the network's end product. In other words, if the network can offer its end product at price $p=r$, its product is on the 
efficient frontier, where the customer-perceived value can not be increased without increasing the price. Furthermore, if the network can price its end product lower than $r(t)$, it determines a new standard for efficiency and thereby gains advantage against competitors.

We wish to study profit-sharing rules that share the profits depending on, first, the network's endproduct price level $p(t)$, second, the reference price $r(t)$, and third, the total saving $s$. The following definition summarises these ideas.

Definition 3.1 A profit-sharing rule $\phi(p, r, s): \mathbb{R}_{+}^{3} \mapsto \mathbb{R}_{+}^{n+2}$ determines the profit-allocation vector $\mathbf{x}$ when the cost-reduction option $s$ is exercised. The profit-allocation given by $\phi$ is denoted by $\left(\phi_{1}, \ldots, \phi_{n+2}\right)$.

The reasons for the above definition are the following. First, if the network's current end-product price is much greater than the reference price, i.e. the difference $p-r$ is big, then the network would prefer a larger share of the saving to be used to price reduction $\left(x_{p}\right)$ than if the difference is small or negative. Second, when $p<r$ the utility from a saving can be allocated to increase the network partners' profits, since the network already creates value more efficiently than its competitors. To reflect the fact that competition and technological development eventually enables higher value creation even with similar costs, also referred to as price erosion, we assume the following:

Assumption 3.2 $r(t)$ is non-increasing in $t$, i.e. $r\left(t_{1}\right) \geq r\left(t_{2}\right), \forall t_{1}<t_{2}$.

Moreover, we assume several desirable characteristics of the profit-sharing rule, described as follows. First, we assume that if the network's end-product price is higher than the reference price, then the end-product price reduction is allocated a greater share than otherwise:

Assumption $3.3 p_{1} \geq r$ and $p_{2}<r \Rightarrow \phi_{n+2}\left(p_{1}, r, s\right)>\phi_{n+2}\left(p_{2}, r, s\right)$.

Second, the basic assumption of an incentive profit-sharing rule is that it is individually rational, i.e. that the subcontractors' share of a saving is non-negative (Luce and Raiffa 1957):

Assumption $3.4 \phi_{i}(\cdot, \cdot, s) \geq 0 \quad \forall s>0, i=1, \ldots, n$.

Third, Pareto optimality guarantees that all utility will be shared: 
Assumption $3.5 \sum_{i} \phi_{i}(p, r, s)=s$.

Finally, the profit to a subcontractor from exercising a cost-reduction option must not increase with time. This is because otherwise the subcontractor has the incentive to hold up the option, which is not globally optimal. Hence, we prefer a profit-sharing rule that is time compatible:

Definition 3.6 The profit-sharing rule $\phi$ is time compatible if $\phi_{i}\left(p\left(t_{1}\right), r\left(t_{1}\right), s\right) \geq \phi_{i}\left(p\left(t_{2}\right), r\left(t_{2}\right), s\right) \quad \forall t_{1}<$ $t_{2}, i=1, \ldots, n$.

Thus, our main assumption is:

Assumption $3.7 \phi$ is time compatible.

Of Assumptions 3.3-3.7, the last one is the most difficult property of a profit-sharing rule. Hence, in the following, we focus on time compatibility when we try to identify suitable profit-sharing rules that work as incentives to exercise cost-reduction options.

\subsection{Profit sharing between one subcontractor and a principal}

We begin our analysis of profit-sharing rules with the case of one subcontractor, whereby the profitallocation vector is $\mathbf{x}=\left(x_{1}, x_{M}, x_{p}\right)$. Moreover, $\left(\phi_{1}, \phi_{2}, \phi_{3}\right)$ denotes the corresponding allocation given by profit-sharing rule $\phi$. Based on the above discussion, we define the following family of profit-sharing rules.

Definition 3.8 $\mathcal{F}_{3}$ is the family of profit-sharing rules $\phi(p, r, s)$, such that $\phi: \mathbb{R}_{+}^{3} \mapsto \mathbb{R}_{+}^{3}$.

In words, a $\phi \in \mathcal{F}_{3}$ is a profit-sharing rule that - when a subcontractor exercises a cost-reduction optiongives the allocation $\left(x_{1}, x_{M}, x_{p}\right)$, accounting for the network's end-product price $p$, the reference price $r$, and the size of the cost saving $s$.

An example of a $\phi \in \mathcal{F}_{3}$ is the proportional utility sharing rule, which has been suggested to offer theoretically sound solutions for profit sharing (e.g. Kalai 1977, Chun and Thomson 1990). It is also the most commonly used rule in business (Thomson 2003): 
Definition 3.9 The proportional profit-sharing rule applied for one subcontractor and principal is

$$
\phi(p, r, s)_{\mathrm{PROP}}=\left\{\begin{array}{l}
\left(\alpha_{1}, \alpha_{2}, \alpha_{3}\right) \cdot s, \text { if } p \geq r \\
\left(\beta_{1}, \beta_{2}, \beta_{3}\right) \cdot s, \text { if } p<r
\end{array}\right.
$$

where $\sum_{i} \alpha_{i}=\sum_{i} \beta_{i}=1, \alpha_{i}, \beta_{i}>0$ and $\alpha_{3}>\beta_{3}$.

In words, when the end-product price is above the reference price, a greater share is allocated to endproduct price-reduction than if $p<r$. This is desirable for the network in order to prevent losing market share if $p>r$. The vectors $\alpha$ and $\beta$ define how aggressively the network transfers the cost-savings to the end-product price. Clearly, $\phi_{\mathrm{PROP}}$ satisfies Assumptions 3.3-3.5. However, it is not obvious when $\phi_{\mathrm{PROP}}$ is time compatible (Assumption 3.7). Thus, the following proposition formalises this for $\mathcal{F}_{3}$.

Proposition 3.10 A profit-sharing rule $\phi \in \mathcal{F}_{3}$ is time compatible if and only if $\phi$ satisfies the following conditions

(i) $\phi_{1}\left(\cdot, r_{1}, \cdot\right) \geq \phi_{1}\left(\cdot, r_{2}, \cdot\right) \quad \forall r_{1}>r_{2}$

(ii) $\phi_{1}(\cdot, \cdot, s) \leq \phi_{1}\left(\cdot, r_{1}, a\right)+\phi_{1}\left(\cdot, r_{2}, b\right) \quad \forall a, b>0, a+b=s$.

Proof See Appendix A

In other words, the above proposition states that if the profit-sharing rule $\phi$ satisfies certain monotonicity (i) and subadditivity (ii) conditions, the value of a cost-reduction option does not increase with time. This implies that it is optimal for the subcontractor to exercise all cost-reduction options as soon as they emerge. To clarify these conditions, the monotonicity condition (i) says that the profit to a subcontractor will not increase if there is price erosion in the end-product. The subadditivity condition (ii), in turn, says that combining two successive cost-reduction options will not result in a greater benefit to the owner than exercising the options separately. This makes it non-profitable for the owner to wait for new options that may emerge. For instance, we can use this result to make $\phi(p, r, s)_{\mathrm{PROP}}$ time compatible:

Corollary 3.11 The proportional profit-sharing rule $\phi(p, r, s)_{\mathrm{PROP}}$ (see Definition 3.9) becomes time compatible if we assume that $\alpha_{1} \leq \beta_{1}$ (by (i) of Proposition 3.10). 


\subsection{Profit sharing with $n$ subcontractors}

In the case with $n$ subcontractors, we search for an allocation $\mathbf{x}=\left(x_{1}, \ldots, x_{n}, x_{M}, x_{p}\right)$. Correspondingly to the setting with one subcontractor, we give the following definition:

Definition 3.12 $\mathcal{F}_{n}$ is the family of profit-sharing rules $\phi(p, r, s)$, such that $\phi: \mathbb{R}_{+}^{3} \mapsto \mathbb{R}_{+}^{n+2}$.

That is, we let $\left(\phi_{1}, \ldots, \phi_{n+2}\right)$ denote the allocation given by profit-sharing rule $\phi \in \mathcal{F}_{n}$. With more than one subcontractor we face the problem that for an individual subcontractor it may be profitable to wait that others exercise their cost-reduction options first. Therefore, in this case Proposition 3.10 does not apply, which can be reasoned through the following counterexample. Consider a rule where $75 \%$ of the cost saving is used in end-product price decrease if $p>r$ and the rest $25 \%$ is given to the owner of the cost-reduction option. Furthermore, if $p \leq r$, then $25 \%$ is used to decrease the price and the rest $75 \%$ is given to the owner. Although this rule satisfies the conditions (i) and (ii) of Proposition 3.10, it is profitable for an owner to wait until others exercise their options and let the end-product price decrease. If the price decreases below the reference level $(p \leq r)$, the owner is better off by exercising his/her options only then, rather than by exercising them earlier when $p>r$. Consequently, this profit-sharing rule is not time compatible with $n \geq 2$.

There are at least two ways to overcome this difficulty. First, the principal can define a $(p, r)$ pair to each subcontractor individually. This would reduce the incentive structure back to the case with only one subcontractor. However, determining and updating $p$ s and $r$ s separately to several subcontractors can be too costly. Second, the principal can try to formulate a profit-sharing rule that uses general values for $p$ and $r$, and is time compatible even with $n$ subcontractors. As was shown by the above counterexample, this requires additional constraints to those introduced in Proposition 3.10.

We consider the broad family of proportional profit-sharing rules with the extra information about the owner of the cost-reduction option. We define this family as follows:

Definition 3.13 $\mathcal{F}_{\mathrm{RWRD}}$ is the family of proportional profit-sharing rules $\phi(p, r, s)$, such that $\phi: \mathbb{R}_{+}^{3} \mapsto$ 
$\mathbb{R}_{+}^{n+2}$,

$$
\phi(p, r, s)=\left\{\begin{array}{l}
\left(\alpha_{1}, \ldots, \alpha_{k}+\delta, \ldots, \alpha_{n+2}\right) \cdot s, \text { if } p \geq r \\
\left(\beta_{1}, \ldots, \beta_{k}+\xi, \ldots, \beta_{n+2}\right) \cdot s, \text { if } p<r
\end{array}\right.
$$

where $\delta, \xi \geq 0$ denote an extra share to the owner of the cost-reduction option, denoted by index $k$. Moreover, $\sum_{i} \alpha_{i}+\delta=\sum_{i} \beta_{i}+\xi=1, \alpha_{n+2}>\beta_{n+2}$, and $\alpha_{i}, \beta_{i}>0 \forall i$.

The family $\mathcal{F}_{\text {RWRD }}$ contains a rich class of profit-sharing rules, which allow the rewarding of the innovator by defining the $\delta, \xi>0$. Moreover, each $\phi \in \mathcal{F}_{\text {RWRD }}$ clearly satisfies Assumptions 3.3-3.5. For time compatibility (Assumption 3.7), we however need to specify additional constraints:

Proposition 3.14 A profit-sharing rule $\phi \in \mathcal{F}_{\mathrm{RWRD}}$ is time compatible if and only if $\xi \leq \delta \leq \xi+\left(\beta_{i}-\alpha_{i}\right)$ $\forall i=1, \ldots, n$.

Proof See Appendix A

On one hand, the above proposition states that when significant price reduction is needed, i.e. when the network's end-product price is higher than that of competitors $(p \geq r)$, then the innovator's extra share $\delta$ should be greater than the extra share $\xi$ when the product is competitively priced $(p<r)$. Otherwise, it could be profitable for the innovator to wait that others exercise their cost-reduction options first. On the other hand, the difference between $\delta$ and $\xi$ must be less than the difference the proportional rule would yield if the subcontractor in question would not have been the innovator, i.e. $\delta-\xi \leq \beta_{i}-\alpha_{i}$. This restriction discourages the innovator to wait for the reference price $r$ to drop.

Thus, Proposition 3.14 yields constraints for rewarding the owner of the cost-reduction option, who can be any of the $n$ subcontractors. These boundaries guarantee that the owner does not profit from delaying the exercise of the options.

The following corollary is a direct consequence of Proposition 3.14.

Corollary 3.15 Let $\phi \in \mathcal{F}_{\mathrm{RWRD}}$ be time compatible. Then, $\beta_{i} \geq \alpha_{i} \forall i=1, \ldots, n$. 
Proof From Proposition 3.14 it follows that, for a time compatible $\phi \in \mathcal{F}_{\mathrm{RWRD}}, \xi \leq \xi+\left(\beta_{i}-\alpha_{i}\right) \forall i=$ $1, \ldots, n \Rightarrow \beta_{i}-\alpha_{i} \geq 0 \forall i=1, \ldots, n$.

In words, Corollary 1 states that when significant price reduction is needed $(p>r)$, then the share to all subcontractors should not be more than when the product is competitively priced $(p<r)$.

We give two examples of profit-sharing rules that are time compatible for $n$ subcontractors. First, the egalitarian rule yields an equal profit to all subcontractors:

Definition 3.16 The egalitarian profit-sharing rule $\phi_{\mathrm{EGAL}} \in \mathcal{F}_{n}$ is

$$
\phi(p, r, s)_{\mathrm{EGAL}}=\left\{\begin{array}{l}
\left(\alpha_{1}, \ldots, \alpha_{n}, \alpha_{n+1}, \alpha_{n+2}\right) \cdot s, \text { if } p \geq r \\
\left(\beta_{1}, \ldots, \beta_{n}, \beta_{n+1}, \beta_{n+2}\right) \cdot s, \text { if } p<r
\end{array}\right.
$$

where $\alpha_{1}=\ldots=\alpha_{n}, \beta_{1}=\ldots=\beta_{n}, \sum_{i} \alpha_{i}=\sum_{i} \beta_{i}=1$, and $\beta_{1}>\alpha_{1}$.

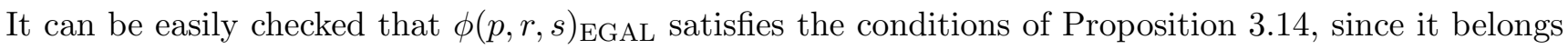
to $\mathcal{F}_{\mathrm{RWRD}}$ with $\delta=\xi=0$. Moreover, $\phi(p, r, s)_{\text {EGAL }}$ is defined so as to follow Assumptions 3.3-3.5. It is also worth noting that in our case the egalitarian rule coincides with the Nash (1950) and Kalai and Smorodinsky (1975) solutions generalised to $n$ players (e.g. Myerson 1997, p. 382).

Second, the combination profit-sharing rule rewards the innovator and the target of the cost reduction:

Definition 3.17 The combination profit-sharing rule is

$$
\phi(p, r, s)_{\mathrm{COMB}}=\left\{\begin{array}{l}
\left(\alpha_{1}, \ldots, \alpha_{k}+\delta, \ldots, \alpha_{n+2}\right) \cdot s, \text { if } p \geq r \\
\left(\beta_{1}, \ldots, \beta_{k}+\xi, \ldots, \beta_{n+2}\right) \cdot s, \text { if } p<r
\end{array}\right.
$$

where $\alpha_{i}=\beta_{i}=0 \forall i \in\{1, \ldots, n\} \backslash\{j\}$ and index $j$ denotes the target of the cost reduction. Moreover, $\delta, \xi>0$ denote the share to the innovator, denoted by index $k$.

Indeed, the target of the cost reduction and the innovator can be distinct, thanks to the open cost structures. Similarly to $\phi(p, r, s)_{\mathrm{EGAL}}$, the combination rule $\phi(p, r, s)_{\mathrm{COMB}}$ belongs to $\mathcal{F}_{\mathrm{RWRD}}$ and $\phi(p, r, s)_{\mathrm{COMB}}$ 
is time compatible if and only if $\alpha_{j}+\delta=\beta_{j}+\xi=\mu$. In words, here Proposition 3.14 implies that the aggregate share of the target and the innovator stays the same regardless of the size of the end-product price $p$ relative to the reference price $r$.

Profit-sharing rules $\phi(p, r, s)_{\text {EGAL }}$ and $\phi(p, r, s)_{\text {COMB }}$ represent the opposing views with respect to equality; the former repays equally, irrespective of the contribution to cost reduction, whereas the latter only compensates the innovator and the target of the cost reduction (other subcontractors benefit indirectly through decreased end-product price). In this perspective, the combination rule is closer to utilitarianism, which strives to maximise the net benefit and is therefore the predominant ideology in business.

\section{Discussion}

\subsection{Implications to network relations}

Willingness to share the cost structure with other subcontractors depends on at least two conditions. First, the trust between the network partners needs to be at a level that rules out the misuse of shared information. In accordance with the contingency theory, the trust level depends on particular circumstances, which vary case by case (Kajüter and Kulmala 2005). Second, from the principal's perspective, the markets for subcontracting are not perfect. Hence, although one subcontractor would find a way to reduce its costs, the principal could not purchase everything from the one due to capacity restrictions. Therefore, from the subcontractor's perspective, it is useful to support the competitiveness of the network by sharing the cost structure with others: innovativeness increases when more people are familiar with the network's cost structure. It is also worth noting that the exact cost figures are not revealed. Sharing the figures would even be questionable in respect of the antitrust law.

In our case, bargaining power plays a role at two levels of supply-chain coordination. First, the everyday improvement is based on trust and spontaneous cost reduction from subcontractors. This is supported by the open books and profit sharing. Here, bargaining power influences the way profit-sharing rules are determined; a powerful principal can demand a larger share of profits. Second, if in the long run a subcontractor is not capable of sufficient cost reduction, it will be changed provided that a substitute 
exists. The availability of alternative subcontractors again reflects the principal's bargaining power.

Even though the principal had bargaining power in terms of threatening to change subcontractors, the execution of this threat, however, involves transaction costs. In our case, instead of using its bargaining power, the principal has chosen to increase trust in the network, assuming to decrease the transaction costs in this way. Since frequent change of subcontractors and fostering trust are mutually exclusive strategies, the principal has in fact temporarily renounced part of its bargaining power. Of course, the principal can at any time change back to competitive strategy and start changing the subcontractors, but this would ruin the slow process of trust creation.

\subsection{Practical implications}

The theoretical analysis of this paper has the following practical implications. First, the network partners need explicit, ex-ante agreed rules for profit sharing in cases of cost-reduction. These rules share the benefit from cost-reductions between the network partners and the end-product price. Second, not just any kind of profit-sharing rule is suitable as an incentive. In a multilateral network, a suitable and simple rule is the combination profit-sharing rule $\phi_{\mathrm{COMB}}$ (see Definition 3.17), which rewards the innovator and the target of the cost-reduction.

If the network is well aware of its position in the markets, it may have knowledge of its competitors' prices. When the network has reached a 'low-enough' level for its end-product price, it is wise to share the benefits from further cost reductions as increased profits to the network partners. A profit-sharing strategy that accounts for market conditions can be easily implemented using the $\phi_{\mathrm{COMB}}$-rule. For instance, let $50 \%$ of the saving be used to decrease the end-product price whenever the price is above the reference price and $10 \%$ otherwise. The rest, i.e. $50 \%$ or $90 \%$, respectively, is allocated to increase the network partners' profits. Moreover, a reward of e.g. $10 \%$ of the saving will be given to the innovator. Using these percentages 
Table 1. Allocation of $4200 €$ using profit-sharing rule $\phi_{\mathrm{XMPL}}(€)$

\begin{tabular}{llllll}
\hline & Target $x_{j}$ & Innovator $x_{k}$ & Principal $x_{M}$ & Price reduction $x_{p}$ & Total $s$ \\
\hline$p \geq r$ & 1680 & 420 & 0 & 2100 & 4200 \\
$p<r$ & 1680 & 420 & 1680 & 420 & 4200 \\
\hline
\end{tabular}

the rule becomes

$$
\phi_{\mathrm{XMPL}}=\left\{\begin{array}{l}
\left(\alpha_{1}, \ldots, \alpha_{k}+\delta, \ldots, \alpha_{n}, 0,0.5\right) \cdot s, \text { if } p \geq r \\
\left(\beta_{1}, \ldots, \beta_{k}+\xi, \ldots, \beta_{n}, 0.4,0.1\right) \cdot s, \text { if } p<r
\end{array}\right.
$$

where for all $i=1, \ldots, n$, the share $\alpha_{i}=\beta_{i}=0.4$ if $i$ is the target of the cost reduction and $\alpha_{i}=\beta_{i}=0$ otherwise. The innovator's share is $\delta=\xi=0.1$. The principal's share is 0 or 0.4 , depending on whether the network's end-product price is, respectively, higher $(p \geq r)$ or lower $(p<r)$ than the competitors' price. Finally, the whole network benefits from the price reduction, which is 0.5 if $p \geq r$ and 0.1 otherwise.

Considering our Roof \& Steel case, table 1 shows the allocation of the annual $4200 €$, which was saved when one subcontractor moved to a smaller office. However, the implementation of the profit-sharing rules at Roof \& Steel is yet to be done. Although as such these sums may sound negligible, there is potential for significant savings when all network partners innovate continuously.

Whether the reference price and the proportional shares are determined by the network's principal alone or together with the subcontractors depends on the culture of the network. Intuitively, if agreed under consensus, the rules may have stronger support than if established unilaterally by the principal. Indeed, when compared to continuous competition, it sounds nicer to pay for creating trust rather than for monitoring network partners. The optimal solution would be to make the network partners compete on cost-efficiency, while still maintaining mutual trust. Steering the network to such relations is a challenge.

\section{$5 \quad$ Summary and conclusions}

In this paper, we have described the case of a roof-assembly network where open-book accounting was successfully implemented. This case raised the motivation to study profit-sharing rules that would work as incentives for network partners to reduce their costs. Identifying opportunities for cost-reduction, i.e. 
cost-reduction options, and measuring the size of the potential savings would be easier due to open books. Strongly synergetic with the open-book practises, the use of incentive profit-sharing rules encourages the network partners to continuous innovation.

Based on the theoretical analysis, we presented two different profit-sharing rules that can be implemented in networks with many subcontractors and that account for the dynamics of the market conditions. First, the egalitarian rule yields an equal share to all subcontractors; second, the combination rule repays only the innovator and the target of the cost reduction. In particular, the combination rule, together with open-book accounting, seems to work as a suitable incentive for continuous cost-reduction and innovation in a network. The combination rule is practically feasible due to its transparency, minimal information needs, and fairness towards contributors, which is essential when fostering trust in collaborative networks.

This paper suggests both empirical and theoretical avenues for further research. First, more case studies of implementing and using profit-sharing rules are called for. Second, from the perspective of the network companies, allocating cost-savings between the companies' profit-increases and the end-product pricereduction is essentially a bicriteria profit-sharing problem; each network company derives utility, first, privately from the increase in its profit, and second, publicly from the decrease of the end-product price, which improves the competitiveness of the network. Hence, the networks could be studied with the concepts of multicriteria game theory with both private criteria, i.e. the companies' profits, and public criteria, i.e. the network's end-product price (Voorneveld and van den Nouweland 2001). Finally, more research is needed to clarify when it is profitable to aim at partnerships and when competition is more efficient.

\section{Acknowledgements}

The authors thank Henri Hytönen, and the two anonymous referees for their helpful comments. During the course of this research, T. Jarimo was with VTT Technical Research Centre of Finland. The research has been partly funded by Emil Aaltonen Foundation and the COBTEC project of the Finnish Funding Agency for Technology and Innovation (Tekes) and the National Workplace Development Programme (Tykes). 


\section{REFERENCES}

BAJARI, P. and TADelis, S., 2001, Incentives versus transaction costs: a theory of procurement contracts. RAND Journal of Economics, 32, (3), 387-407.

Bakos, J. Y. and Brynjolfsson, E., 1993, From vendors to partners: Information technology and incomplete contracts in buyer-supplier relationships. Journal of Organizational Computing, 3, (3), 301-328.

Boer, H., Gertsen, F., Kaltoft, R. M. and Steendahl Nielsen, J., 2005, Factors affecting the development of collaborative improvement with strategic suppliers. Production Planning \& Control, 16, (4), 356-367.

Cachon, G. P. and Lariviere, M. A., 2005, Supply chain coordination with revenue-sharing contracts: Strengths and limitations. Management Science, 51, (1), 30-44.

Cagliano, R., Caniato, F., Corso, M. and Spina, G., 2005, Collaborative improvement in the extended manufacturing enterprise: lessons from an action research process. Production Planning $\mathcal{G}^{\circ}$ Control, 16, (4), 345-355.

Chun, Y. and Thomson, W., 1990, Bargaining with uncertain disagreement points. Econometrica, 58, (4), 951-959.

Corbett, C. J. and DeCroix, G. A., 2001, Shared-savings contracts for indirect materials in supply chains: Channel profits and environmental impacts. Management Science, 47, (7), 881-893.

Cousins, P. D., 2002, A conceptual model for managing long-term inter-organisational relationships. European Journal of Purchasing \& Supply Management, 8, 71-82.

Gertsen, F., 2003, Editorial: Continuous innovation. International Journal of Technology Management, 26, (8), 801-804.

Gulati, R., Nohria, N. and Zaheer, A., 2000, Strategic networks. Strategic Management Journal, 21, (3), 203-215.

Jarimo, T., Pulkkinen, U. and Salo, A., 2005, Encouraging suppliers to process innovations: A game theory approach. International Journal of Technology Intelligence and Planning, 1, (4), 403-423. 
Kajüter, P. and Kulmala, H. I., 2005, Open-book accounting in networks: Potential achievements and reasons for failures. Management Accounting Research, 16, (2), 179-204.

KALAI, E., 1977, Proportional solutions to bargaining situations: Interpersonal utility comparisons. Econometrica, 45, (7), 1623-1630.

Kalai, E. and Smorodinsky, M., 1975, Other solutions to nash's bargaining problem. Econometrica, 43, (3), 513-518.

Luce, R. D. and RaIffa, H., 1957, Games and Decisions (John Wiley \& Sons).

Mouritsen, J., Hansen, A. and Hansen, C. O., 2001, Inter-organizational controls and organizational competencies: episodes around target cost management/functional analysis and open book accounting. Management Accounting Research, 12, (2), 141-256.

Myerson, R. B., 1997, Game Theory: Analysis of Conflict (First Harvard University Press).

NASH, J. F., 1950, The bargaining problem. Econometrica, 18, (2), 155-162.

Pfohl, H.-C. and Buse, H. P., 2000, Inter-organizational logistics systems in flexible production networks: An organizational capabilities perspective. International Journal of Physical Distribution $\mathcal{G}$ Logistics Management, 30, (5), 388-408.

Porter, M. E., 1996, What is strategy? Harvard Business Review, 74, (6), 61-78.

Rese, M., 2005, Successful and sustainable business partnerships: How to select the right partners. Industrial Marketing Management, 35, (1), 72-82.

SCHERER, F. M., 1964, The theory of contractual incentives for cost reduction. The Quarterly Journal of Economics, 78, (2), 257-280.

Thomson, W., 2003, Axiomatic and game-theoretic analysis of bankruptcy and taxation problems: a survey. Mathematical Social Sciences, 45, 249-297.

Voorneveld, M. and VAn DEN NOUweland, A., 2001, Cooperative multicriteria games with public and private criteria; an investigation of core concepts, University of Oregon Economics Department Working Papers 2001-11, University of Oregon Economics Department, available online at http://ideas.repec.org/p/ore/uoecwp/2001-11.html (accessed January 10, 2008). 


\section{Appendix A: Proofs of propositions}

Proof of Proposition 3.10 ' $\Rightarrow$ ' Assumptions: $r\left(t_{1}\right) \geq r\left(t_{2}\right) \forall t_{1}<t_{2}$ (Assumption 3.2) and $\phi_{1}\left(t_{1}\right) \geq \phi_{1}\left(t_{2}\right)$ $\forall t_{1}<t_{2}$ (time compatibility).

(i) $t$ increases strictly when $r$ decreases $\Rightarrow \phi_{1}$ is non-increasing when $r$ decreases.

(ii) Let $a$ denote the saving from a cost-reduction option that a subcontractor observes at time $t_{1}$, valued at $\phi_{1}\left(p\left(t_{1}\right), r\left(t_{1}\right), a\right)$. Moreover, let $b$ denote the saving from another cost-reduction option that emerges at time $t_{2}>t_{1}$, valued at $\phi_{1}\left(p\left(t_{2}\right), r\left(t_{2}\right), b\right)$. Since $\phi_{1}\left(t_{1}\right)>\phi_{1}\left(t_{2}\right) \forall t_{1}<t_{2}$, then $\phi_{1}\left(p\left(t_{2}\right), r\left(t_{2}\right), a\right)<$ $\phi_{1}\left(p\left(t_{1}\right), r\left(t_{1}\right), a\right)$. Hence, $\phi_{1}\left(p\left(t_{2}\right), r\left(t_{2}\right), s\right) \leq \phi_{1}\left(p\left(t_{1}\right), r\left(t_{1}\right), a\right)+\phi_{1}\left(p\left(t_{2}\right), r\left(t_{2}\right), b\right)$, when $s=a+b$.

' $\Leftarrow$ ' Assumptions: $\phi_{1}\left(\cdot, r_{1}, \cdot\right)>\phi_{1}\left(\cdot, r_{2}, \cdot\right) \forall r_{1}>r_{2}$ and $r\left(t_{1}\right) \geq r\left(t_{2}\right) \forall t_{1}<t_{2}$ (Assumption 3.2)

Let $a$ and $b$ denote the savings from two cost-reduction options that emerge at times $t_{1}$ and $t_{2}$, respectively. Furthermore, assume that $t_{1}<t_{2}$. Since $\phi_{1}(\cdot, \cdot, s) \leq \phi_{1}(\cdot, \cdot, a)+\phi_{1}(\cdot, \cdot, b)$, the emergence of $b$ does not increase the value of $a$. Moreover, since $\phi_{1}$ is non-increasing when $r$ decreases, and $r$ is non-increasing in $t$ (Assumption 3.2), postponing the exercise of a cost-reduction option does not increase its value through $r$. Hence, $\phi_{1}\left(t_{1}\right) \geq \phi_{1}\left(t_{2}\right) \forall t_{1}<t_{2}$.

Proof of Proposition 3.14 There are two occasions when it may be beneficial to the owner of a costreduction option $s_{1}$ to postpone its exercise. First, if $p \geq r$, the owner may wait that other subcontractors execute their cost-reduction options so that $p$ decreases below $r$. Let $t_{0}$ denote the time when $p$ goes below $r$, and let $\tau_{1}$ denote the time when the owner exercises $s_{1}$. Moreover, let $\phi_{k}^{\prime}$ and $\phi_{k}^{\prime \prime}$ denote the benefit to the owner when $\tau_{1}<t_{0}$ and $\tau_{1}>t_{0}$, respectively. Let $s_{2}$ denote the total saving from the others' cost-reduction options. Without loss of generality, let us assume that $s_{1}<s_{2}=p-r$. Thus, $\phi_{k}^{\prime}=\left(\alpha_{k}+\delta\right) s_{1}+\left(s_{2}-s_{1}\right) \alpha_{k}+s_{1} \beta_{k}$ and $\phi_{k}^{\prime \prime}=\alpha_{k} s_{2}+\left(\beta_{k}+\xi\right) s_{1}$. Furthermore, $\phi$ is time compatible if and only if $\phi_{k}^{\prime} \geq \phi_{k}^{\prime \prime} \Leftrightarrow\left(\alpha_{k}+\delta\right) s_{1}+\left(s_{2}-s_{1}\right) \alpha_{k}+s_{1} \beta_{k} \geq \alpha_{k} s_{2}+\left(\beta_{k}+\xi\right) s_{1} \Leftrightarrow \alpha_{k} s_{1}+\delta s_{1}+s_{2} \alpha_{k}-s_{1} \alpha_{k}+s_{1} \beta_{k} \geq$ $\alpha_{k} s_{2}+\beta_{k} s_{1}+\xi s_{1} \Leftrightarrow \delta \geq \xi$. Second, if $p<r$, the owner can wait so that, at time $t_{1}, r$ decreases below $p$, in which case the benefit to the owner may not increase (by (i) of Proposition 3.10). Now, let $\phi_{k}^{\prime}=\left(\beta_{k}+\xi\right) s_{1}$ and $\phi_{k}^{\prime \prime}=\left(\alpha_{k}+\delta\right) s_{1}$ denote the benefit to the owner when $\tau_{1}<t_{1}$ and $\tau_{1}>t_{1}$, respectively. Again, $\phi$ is time compatible if and only if $\phi_{k}^{\prime} \geq \phi_{k}^{\prime \prime} \Leftrightarrow \beta_{k}+\xi \geq \alpha_{k}+\delta \Leftrightarrow \delta \leq \xi+\beta_{k}-\alpha_{k}$. 